This item was submitted to Loughborough's Research Repository by the author.

Items in Figshare are protected by copyright, with all rights reserved, unless otherwise indicated.

\title{
Methodology for the design of controlled low-strength materials. Application to the backfill of narrow trenches
}

PLEASE CITE THE PUBLISHED VERSION

https://doi.org/10.1016/j.conbuildmat.2014.09.008

\section{PUBLISHER}

(C) Elsevier

\section{VERSION}

AM (Accepted Manuscript)

\section{PUBLISHER STATEMENT}

This work is made available according to the conditions of the Creative Commons Attribution-NonCommercialNoDerivatives 4.0 International (CC BY-NC-ND 4.0) licence. Full details of this licence are available at: https://creativecommons.org/licenses/by-nc-nd/4.0/

\section{LICENCE}

CC BY-NC-ND 4.0

\section{REPOSITORY RECORD}

Blanco, Ana, Pablo Pujadas, Sergio H. Cavalaro, and Antonio Aguado. 2019. "Methodology for the Design of Controlled Low-strength Materials. Application to the Backfill of Narrow Trenches". figshare.

https://hdl.handle.net/2134/32300. 


\title{
Methodology for the design of controlled low-strength materials. Application to the backfill of narrow trenches.
}

\author{
A. Blanco ${ }^{*}$, P. Pujadasa, S. Cavalaro ${ }^{a}$, A. Aguado ${ }^{a}$ \\ a Department of Construction Engineering, Universitat Politècnica de Catalunya-BarcelonaTech, UPC, Jordi Girona 1-3, \\ 08034 Barcelona, Spain. \\ * Corresponding author. Tel.: +34-93-401-7825; fax: +34-93-401-1036; e-mail: ana.blanco@upc.edu
}

\begin{abstract}
The design of controlled low-strength materials (CLSM) is generally based on experimental approaches without considering an efficient use of the component materials. The present study proposes a general methodology for the design of optimised CLSM that includes the definition of the mechanical requirements through numerical simulations with FEM and an experimental procedure to define the mix by optimising the aggregate skeleton, the content of cement and the use of admixtures and additions. Moreover, the methodology is applied to the backfill of narrow trenches.
\end{abstract}

Keywords: Controlled low-strength materials, design, narrow trench, backfill, simulation

\section{Introduction}

The use of narrow trenches for the installation of flexible pipelines of small diameter is a common technique for the construction of water, electricity, lighting and gas networks. One of the advantages of this technique is the limited interference with other services or traffic during construction. After the trench is excavated, a backfill material is used to fill the void left behind as well as to provide the support for the pipe and the surface elements. For that purpose, it is common to apply a controlled low-strength material (CLSM) as opposed to the use of traditional compacted granular fill.

As a backfill material, the CLSM requires a consistency close to that of selfcompactability in order to reach tight or restricted-access areas [1] and a compressive strength that allows fast reestablishment of traffic without settling under traffic load, but also that may be easily excavated with conventional digging equipment [2]. These contradictory requirements represent a challenge when designing the mix proportions since both the deformability and the compressive strength of the material must be balanced and limited to a certain value.

In general, the definition of the mix proportions of CLSM are based on empirical approaches $[3,4]$ that do not always consider the optimisation of the materials used. In order to develop an optimised CLSM, the design of the mix should be preceded by a 
technical base assessment of the requirements according to the application for what it is intended (e.g. backfills, structural fills, insulating or isolation fills, pavement bases, void filling, etc.). Afterwards, a series of tests should be performed to ensure that the resulting material fulfils the requirements.

Considering the abovementioned, the present study aims at defining a general methodology for the design of optimised CLSM. This approach proposes the assessment of the requirements through a numerical simulation of the application and an experimental procedure to optimise each of the components of the CLSM. Furthermore, this methodology is subsequently applied to a real case of a CLSM for the backfill of narrow trenches.

The main interest of the study consists in the development of a straightforward methodology that may be employed for any application. The novelty of the methodology is the use of a numerical analysis by means of FEM for defining the mechanical requirements of the CLSM since this type of studies are found in the literature for traditional compacted granular fill (e.g. for trenches $[5,6]$ ) but are scarce for CLSM. Likewise, the methodology provides a series of tests for optimising the aggregate skeleton, the cement content and use of admixture that have proved to be convenient for the procedure.

\section{Methodology for the design of optimised CLSM}

The methodology proposed is summarized in the flow diagram presented in Fig.1. The main requirements of a CLSM, according to what was previously exposed, are the workability in fresh-state and the compressive strength in the hardened state. These two properties and, therefore, the requirements are dependant of the type of application for what the material is intended.

In general, the workability of the CLSM should be close to self-compactability to avoid the need of vibration. Hence, the design of the mix should be conducted to attain that consistency. In order to set the value of compressive strength that materials should reach to fulfil the requirements, a FEM analysis is performed. This type of analysis allows reproducing the loading and boundary conditions of the CLSM and identify the compressive strength required to guarantee no settlements and easy excavation. 


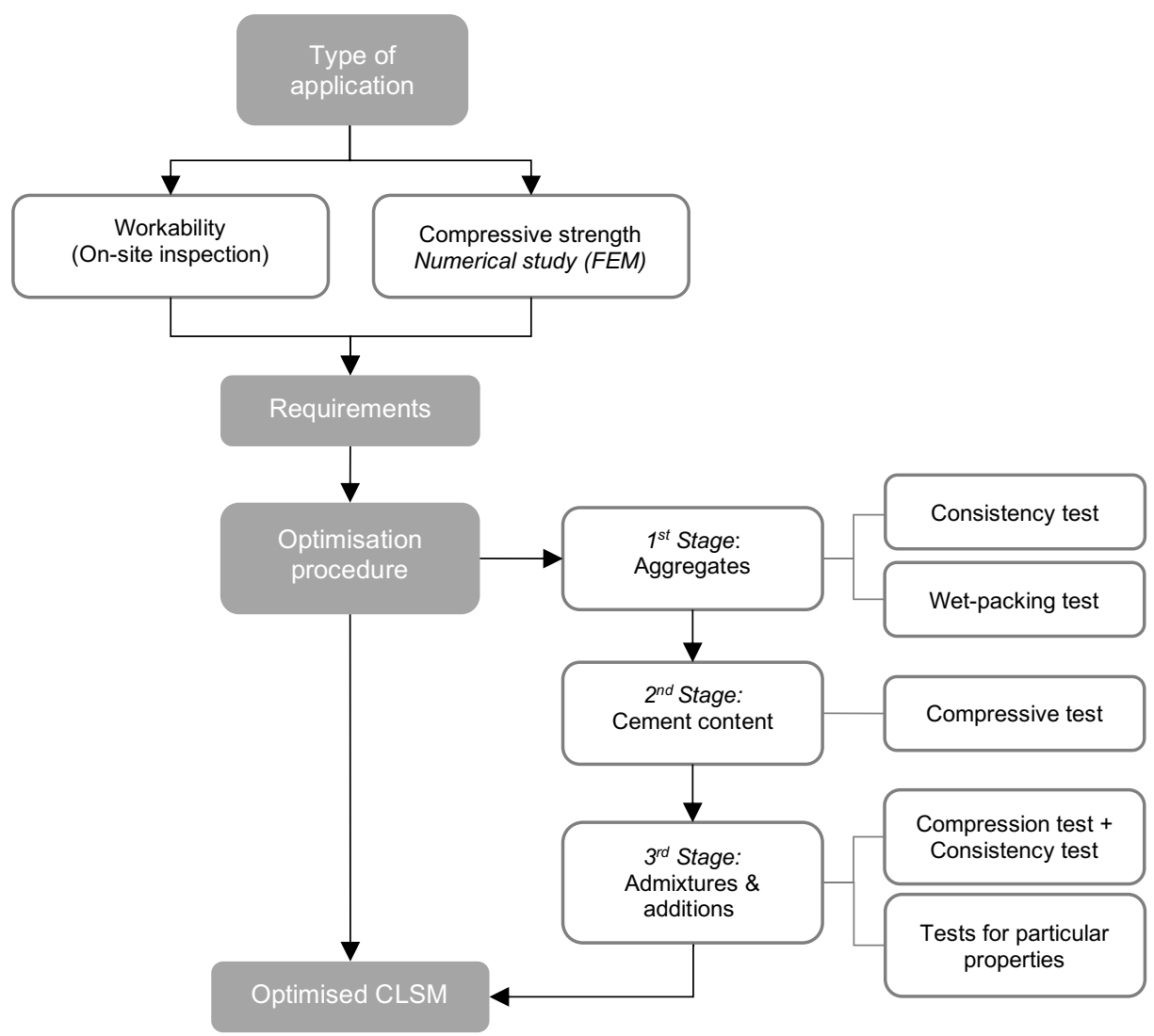

Fig. 1 General methodology for the design of optimised CLSM.

Afterwards, when the desired workability and compressive strength have been defined, the optimisation procedure of the mix is conducted in three stages: first the aggregate skeleton is optimised, subsequently the amount of cement and, finally, the use of admixtures and additions.

The optimisation of the aggregate skeleton consists in finding the combination of the aggregates that provides the maximum compactness and the desired workability. For that, two tests are defined at this stage: a wet-packing test $[7,8]$ and the consistency test according to UNE-EN 1015-3:2000 [9].

The first one allows determining the solid concentration and the voids ratio, which are key parameters in the optimisation since a reduction of the voids could contribute to reduce the consumption of cement and problems regarding segregation. Furthermore, a more compact matrix would be less deformable, which is very convenient considering the applications of CLSM. The second one provides information regarding the consistency through the extent of the flow. Notice that a small content of cement (e.g. 40 
$\left.\mathrm{kg} / \mathrm{m}^{3}[7]\right)$ may be used to perform such tests given that the assessment of the strength is not in the scope of this stage.

The subsequent stage of the methodology is the optimisation of the amount of cement considering the aggregate skeleton obtained from the previous stage. For that purpose, the compression test according to UNE-EN 12390:2009 [10] is proposed to assess mixes with different cement contents and determine which is adequate to fulfil the requirements set previously.

Finally, the last stage of the methodology summarized in Fig.1 is the optimisation of the use of admixtures and additions. Besides the traditional admixtures and additions (e.g. air-entraining admixtures, foaming agents or fly ash [2]), CLSM support the use of recycled or reused components from diverse origin such as recycled fine aggregates [11], waste materials, industrial by-products [12-15] and mine tailings [16].

In case any of the abovementioned materials are used, the consistency test and compression test previously proposed should be performed to assess the influence of such materials on the workability and compressive strength of the mix. Furthermore, if the additive or admixture has a particular property (e.g. expansive additions) this should be assessed to determine the effect on the fresh-state and hardened-state properties of the CLSM. In the case of an expansive addition, the resulting expansion should be measured.

The approach followed in this optimisation procedure is characterised by the use of watersolid ratios $(\mathrm{w} / \mathrm{s})$ instead of water-cement ratios $(\mathrm{w} / \mathrm{c})$. Notice that the terminology "solids" includes aggregates and cement. This provides a great flexibility in the sense that, for the value of $w / s$ that leads to the workability desired, the cement content may be varied in order to increase or decrease the strength of the CLSM by replacing the equivalent amount of aggregates without affecting the workability. This is possible also due to the small content of cement used in this type of mixes in comparison with that usually found in conventional mortar. If the content of cement was an important part of the total volume, its influence in the consistency should be taken into account.

In subsequent sections, the methodology presented is applied to the case of a backfill material for a narrow trench for natural gas plastic pipelines.

\section{Numerical simulation}

\subsection{Description of the model}


In order to determine the mechanical requirements of a CLSM for the backfill of a narrow trench, a numerical study is conducted with the finite element software DIANA 9.1 [17]. This software is chosen to simulate the behaviour of the trench due to its extensive material library and analysis capabilities. A 3D model is considered and the four-node prismatic elements are used for the meshing, with a denser refinement in the trench and around the pipeline.

Fig. 2 depicts the geometry of the model and the location where the traffic load is applied (further detail on the definition and location of the load is given in subsequent sections). The geometry is defined according to the hypothesis that the surrounding soil may present layers with different properties or the constructive process adopted. Notice that the dimensions of the layers (both in depth and width) are defined based on the analysis of typical dimensions of narrow trenches found in practice and in the literature. Particularly, the width of the model $(1.65 \mathrm{~m})$ was defined so that it was representative of the actual situation and that its dimension did not affect the results of the simulation.

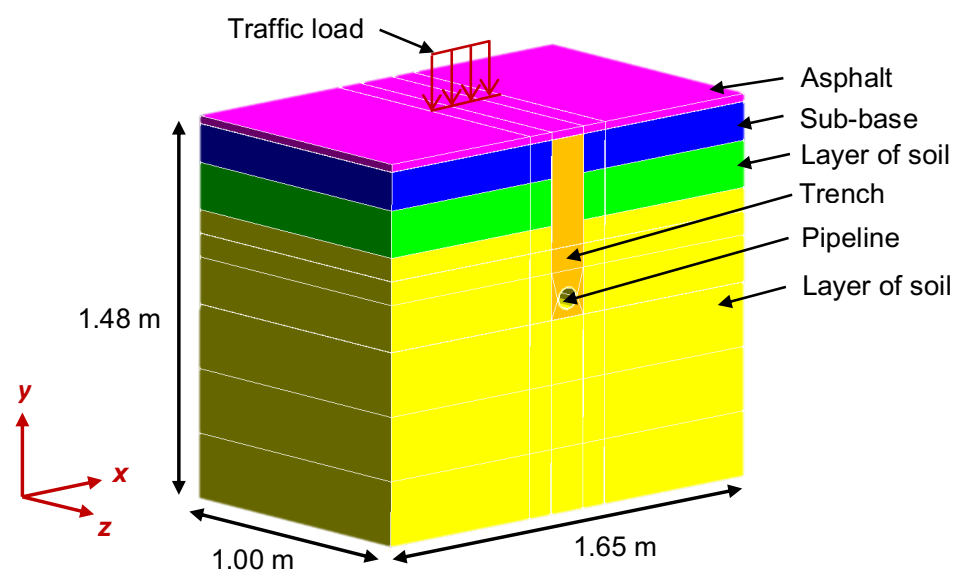

Fig.2 Geometry of the 3D model in DIANA 9.1.

Taking into account the abovementioned, the following layers and their corresponding depths are considered: an asphalt pavement of $0.03 \mathrm{~m}$, a sub-base layer of $0.15 \mathrm{~m}$, soil layer with a total depth of $1.30 \mathrm{~m}$. Notice that the old and new asphalt pavement (after the trench is closed) overlap $0.10 \mathrm{~m}$. The width of the narrow trench is $0.15 \mathrm{~m}$ and a depth of $0.70 \mathrm{~m}$. On top of the trench there is the $0.03 \mathrm{~m}$ layer of asphalt pavement. The width of the surrounding soil at each side of the trench is $0.75 \mathrm{~m}$ and the total depth of the model, considering the pavement, the sub-base and the soil, is $1.48 \mathrm{~m}$. 
The diameter of the pipeline, which is simulated up to a length of $1.0 \mathrm{~m}$, is $90 \mathrm{~mm}$ and lies on $0.03 \mathrm{~m}$ of CLSM. Notice that uniform bedding support under the pipeline was assumed in the simulation.

The boundary conditions set in the model correspond to a constraint support in axis $z$ and an elastic support in axes $x$ and $y$ with a spring constant $(k)$ of equal to $10^{9}$.

\subsection{Materials}

The definition of the materials in the model is conducted based on the wide range of situations that may be found in practice when excavating a trench, such as several layers and types of soils. These situations in practice may lead to different requirements of the CLSM and, therefore, must be contemplated in the numerical study. For that reason, a parametric study is performed in which the variables are the properties of the soil and the CLSM (their properties are defined in the subsequent section). The properties of the asphalt pavement, the sub-base material and the pipeline remain constant given that their influence on the overall behaviour and the requirements of the CLSM are minor compared if compared to that of the soil since their characteristics are easier to control.

Fig. 3 shows an outline of the approach followed for the numerical simulations of the trench. Notice that the properties of the materials are the input for the model and are categorized in variables and data according to the previously mentioned.

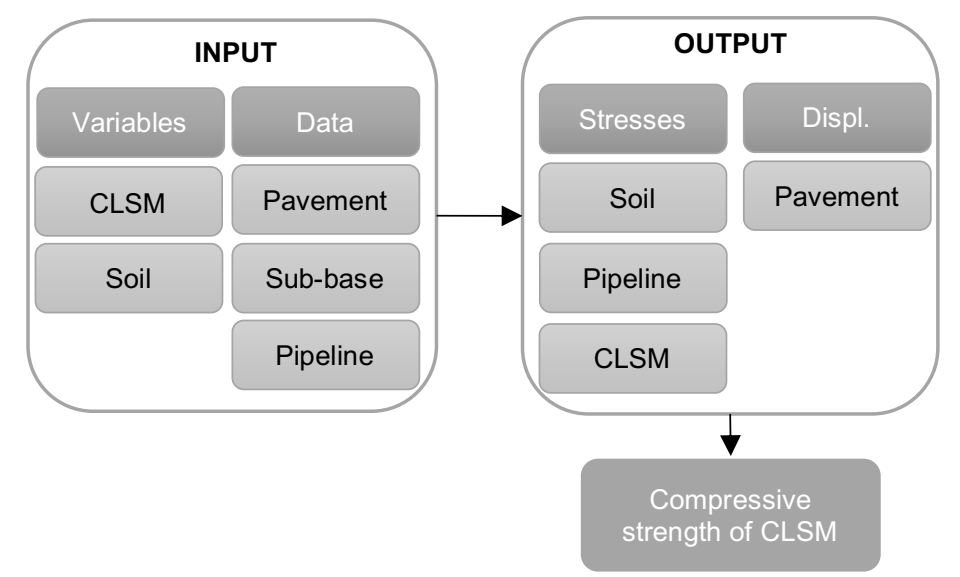

Fig.3 Approach followed in the numerical simulation of the trench.

Among the results obtained with the simulation, the analysis focus on the displacement in the asphalt pavement due to the traffic loads, the maximum stresses in the CLSM (or trench), in the soil and in the pipeline, which are represented in Fig.3 as the output. Finally, based on the results a compressive strength for the CLSM is defined. 
In general, the narrow trenches are excavated in pavements that have been used for several months or years, which indicates that the soil may be considered as consolidated. As a result, high values of stresses are not expected and, therefore, linear-elastic behaviour of the materials is considered.

For that reason, the properties of the materials are defined by the modulus of elasticity $(E)$ and the Poisson coefficient (v) according to the literature [18]. For the material of the sub-base layer, a granular fill is considered and the pipeline is made of high density polyethylene (PE). Table 1 presents the values of $E$ and $v$ considered in each case.

Table 1. Properties of the materials considered as data.

\begin{tabular}{lcc}
\hline \multicolumn{1}{c}{ Materials } & $\begin{array}{c}\text { Modulus of } \\
\text { elasticity (MPa) }\end{array}$ & $\begin{array}{c}\text { Poisson coefficient } \\
(-)\end{array}$ \\
\hline Asphalt pavement & 3000 & 0.25 \\
\hline Sub-base material & 350 & 0.35 \\
\hline Pipeline (PE100HD) & 900 & 0.38 \\
\hline
\end{tabular}

Two types of contacts between layers are defined in the model: a perfect contact and a weak contact. In the first case, for the horizontal contacts between the layers of asphalt pavement, sub-base material and soil and for the vertical contact between the old and new asphalt pavement a linear-elastic contact with a high stiffness is assumed $\left(K=10^{14} \mathrm{~N} / \mathrm{m}\right)$. The second type corresponds to the vertical contact between the soil and the trench. Given the possible shrinkage of the CLSM, a weak contact is assumed by defining a low stiffness $(\mathrm{K}=1 \mathrm{~N} / \mathrm{m})$.

\subsection{Variables considered}

The variables considered in the numerical simulation are, as previously introduced, the properties of soil and the CLSM. Table 2 presents the properties the variables considered in the parametric study. The three types of soil were defined according to the literature [19]. The value of $v$ remains constant since it is a common value representative of different types of soils. The properties of 5 types of CLSM were defined according to the values of $E$ and $v$. Based on the literature [14], $E$ may assume values ranging from 100 $\mathrm{MPa}$ to $300 \mathrm{MPa}$. 
Table 2. Variables considered in the parametric study.

\begin{tabular}{ccccc}
\hline \multicolumn{2}{c}{ Variables } & $\begin{array}{c}\text { Modulus of } \\
\text { elasticity (MPa) }\end{array}$ & $\begin{array}{c}\text { Poisson } \\
\text { coefficient (-) }\end{array}$ & Description \\
\hline \multirow{3}{*}{ Soil } & I & 60 & 0.3 & Hard clay, dense sand or loose gravel \\
\cline { 2 - 5 } & II & 100 & 0.3 & Hard clay, sandy clay or loose gravel \\
\cline { 2 - 5 } & III & 200 & 0.3 & Sandy clay or dense gravel \\
\hline \multirow{4}{*}{ CLSM } & I & 100 & 0.2 & - \\
& II & 150 & 0.2 & - \\
& III & 200 & 0.2 & - \\
& IV & 250 & 0.2 & - \\
\cline { 2 - 5 } & V & 300 & 0.2 & - \\
\hline
\end{tabular}

Besides simulating the behaviour of the trench with the three soils defined in Table 2, the possibility of having two different soils surrounding the trench is also studied. For that, an upper layer with the properties of soil I and a lower layer of soil II were modelled. In such case, the depths of the upper layer and the bottom layer are $0.30 \mathrm{~m}$ and $0.93 \mathrm{~m}$, respectively. Therefore, the trench of $0.70 \mathrm{~m}$ of depth is surrounded by $0.15 \mathrm{~m}$ of the subbase material, subsequently there is a layer of $0.30 \mathrm{~m}$ of soil I and the remaining depth of the trench is surrounded by soil II.

\subsection{Traffic load}

The traffic load applied in the model is defined according to international traffic regulations, which specify the maximum load allowed per tyre. The regulations taken as a reference are the French and Spanish traffic regulations [20, 21]. Considering the critical case of double tyres, the maximum load per axis specified is $130 \mathrm{kN}$ in the former and $115 \mathrm{kN}$ in the latter. To be on the safe side and to comply with both regulations, the highest value was used in all simulations.

To simplify the model and reduce the number of elements, the load is not applied to the surface of the tyre footprint. Instead, it is concentrated on the generatrix of the tyre, which also contributes to an assessment of the behaviour in a more critical situation that should be on the safe side.

\subsection{Results}

\section{Analysis of the surrounding soil}

Fig.4 depicts other results obtained from the analysis regarding the compressive stresses in the surrounding soil. The evolution of the compressive stresses with the modulus of 
elasticity of the CLSM is plotted for different types of soil. Notice that the case with two types of soil is referred to as $(E=60-100 \mathrm{MPa})$.

The curves in Fig.4a reveal that the compressive stresses in the soil decrease with the modulus of elasticity of the CLSM due to the higher bearing capacity of the CLSM with bigger elastic modulus. For example, when the modulus of elasticity of CLSM increases from $100 \mathrm{MPa}$ to $300 \mathrm{MPa}$ the decrease of the stresses in the soil is $34.9 \%$ for a soil of 60 $\mathrm{MPa}$ and $32.0 \%$ for a soil of $200 \mathrm{MPa}$. These results reveal that the decrease observed is not significantly influenced by the type of soil.

a)

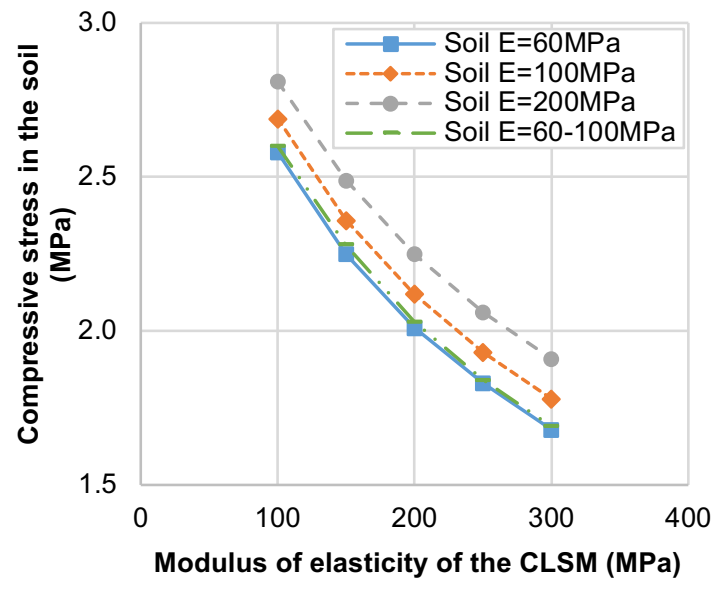

b)

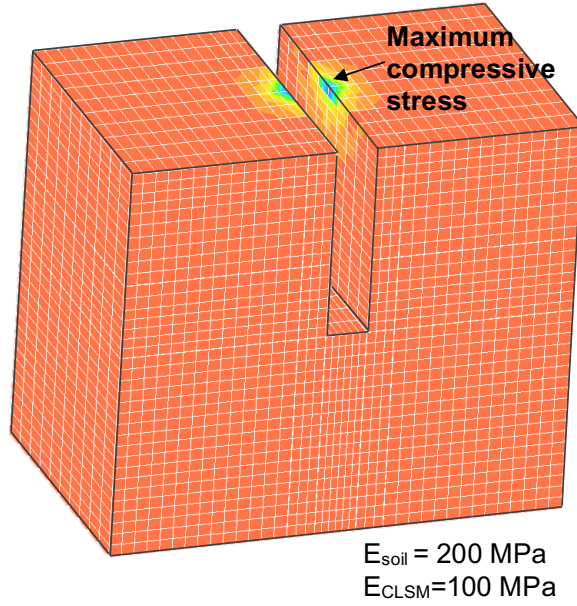

Fig. 4 a) Influence of the modulus of elasticity of the CLSM on the compressive stress and b)

stress distribution in the surrounding soil a soil of $200 \mathrm{MPa}$ and CLSM of $100 \mathrm{MPa}$.

Furthermore, the stresses are lower as the soil becomes more flexible. The increase of the stresses in the soil when it becomes stiffer is $40.9 \%$ for a modulus of the CLSM of $100 \mathrm{MPa}$. The highest stresses in the soil were obtained for stiff soil $(E=200 \mathrm{MPa})$ and a flexible CLSM ( $E=100 \mathrm{MPa})$ and the compressive stress in the soil is $2.8 \mathrm{MPa}$. The results also indicate that the case with two types of soil $(E=60-100 \mathrm{MPa})$ are very similar to the ones obtained for the soil of $60 \mathrm{MPa}$. Hence, the response of the soil is governed by the top surface which is most flexible.

The distribution of stresses in Fig. $4 \mathrm{~b}$ indicates that the maximum compressive stress is located at the boundary of the soil with the trench, particularly concentrated in the zone where the traffic load was defined (notice that the load was concentrated in the generatrix of the tyre, see section 3.5 Traffic load). 


\section{Analysis of the pipeline}

For the case of the pipeline, presented in Fig.5a, the trend is not as marked as for the soil. For flexible soils, the tendency of the compressive stresses is to decrease slightly, in particular an $8.6 \%$ for a soil of $60 \mathrm{MPa}$. However, for stiffer soils (e.g. $E=200 \mathrm{MPa}$ ), the compressive stresses in the pipeline increase slightly, thus leading to a difference between the most flexible CLSM (100 MPa) and the stiffest (300 MPa) of only $1.9 \%$.
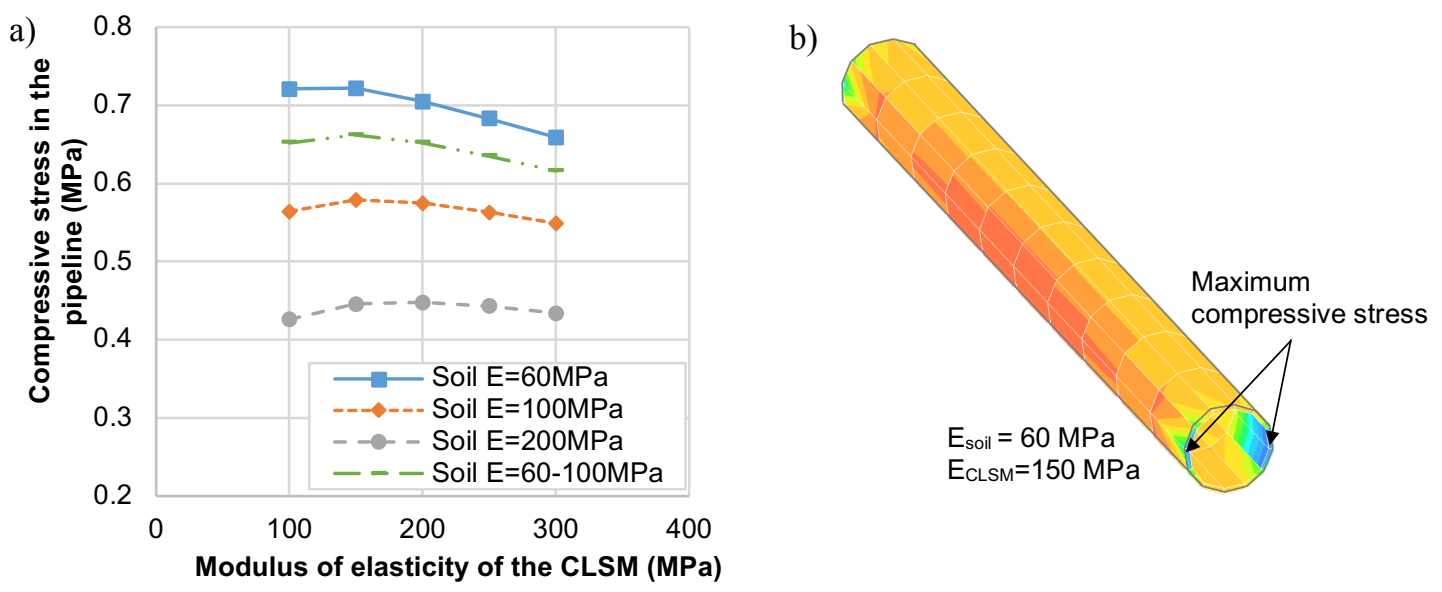

Fig.5 a) Influence of the modulus of elasticity of the CLSM on the compressive stress and b) stress distribution in the pipeline a soil of $60 \mathrm{MPa}$ and CLSM of $150 \mathrm{MPa}$.

With regards to the modulus of elasticity of the soil, as the soil turns stiffer the stresses in the pipeline are smaller due to the higher bearing capacity of the soil. Notice that for a CLSM of $100 \mathrm{MPa}$, the compressive stress is reduced $40.9 \%$ when the modulus of elasticity of the soil increases from $60 \mathrm{MPa}$ to $200 \mathrm{MPa}$. The biggest compressive stress (0.7 MPa) occurs for the more flexible soil and CLSM. Contrarily to what was observed in Fig.4a, the case with two types of soils presents a noticeable difference with the other cases, exhibiting values of stress between those of the cases with only one layer of soil of $60 \mathrm{MPa}$ and $100 \mathrm{MPa}$.

Fig. $5 \mathrm{~b}$ shows the distribution of stresses along the pipeline. The maximum compressive stresses are observed at the ends of the pipeline and, particularly, in the haunches rather than at the top or the bottom.

\section{Analysis of the CLSM in the trench}

Fig.6a presents the evolution of the maximum compressive stresses in the CLSM of the trench with the modulus of elasticity of the CLSM for different soil configurations. The 
curves reveal that the compressive stresses in the trench become higher as the modulus of elasticity of the CLSM increases. This outcome was expected since the increasing stiffness of the material with regards to the surrounding soil leads to the bearing of higher values of stress.

a)

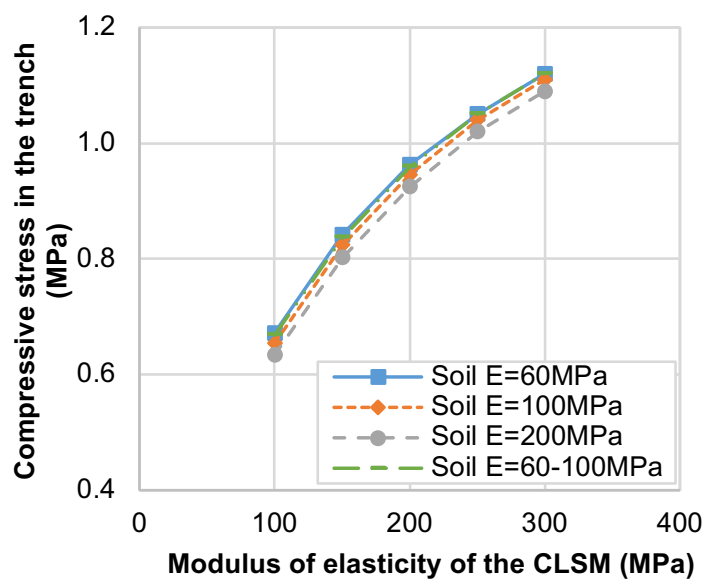

b)

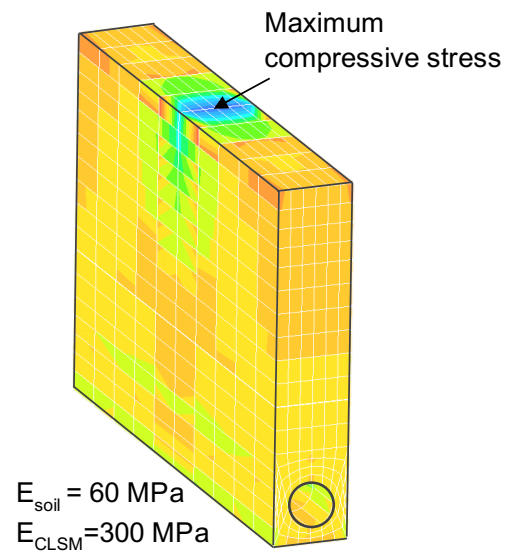

Fig. 6 a) Influence of the modulus of elasticity of the CLSM on the compressive stresses in the trench and b) stress distribution in the trench for a soil of $60 \mathrm{MPa}$ and CLSM of $300 \mathrm{MPa}$.

For a soil of $60 \mathrm{MPa}$, the increase in the modulus of elasticity of the CLSM from 100 $\mathrm{MPa}$ to $300 \mathrm{MPa}$ represents an increase of the maximum compressive stress in the trench of $66.7 \%$ and for a soil of $200 \mathrm{MPa}$ this percentage is $71.9 \%$. Fig. $6 \mathrm{~b}$ shows the stress distribution in the trench with the maximum compressive stress located at the top of the trench where the loading along the generatrix of the tyre was defined.

The worst-case scenario with regards to the requirements of compressive strength of the CLSM corresponds to the most flexible soil $(E=60 \mathrm{MPa})$ and the stiffest CLSM $(E=300$ $\mathrm{MPa}$ ). In this case the maximum compressive stress exhibited is $1.12 \mathrm{MPa}$.

The curves also reveal that the influence of the modulus of elasticity of the soil is very small since the differences observed between the softest and the stiffest soil are $6.0 \%$ for a CLSM of $100 \mathrm{MPa}$ and $2.8 \%$ for a CLSM of $300 \mathrm{MPa}$. The reason for such small differences may be attributed to the fact that the maximum stress is located too close to the surface so that the influence of the surrounding soil is diminished.

\section{Analysis of the displacement in the asphalt pavement}

The curves in Fig. 7 show the evolution of the displacement of the asphalt pavement with the modulus of elasticity of the CLSM. In this case, the opposite trend is observed since, 
as the modulus of elasticity of the CLSM increases, the displacement of the asphalt pavement becomes smaller due to the increasing stiffness of the CLSM.

In addition to that, a noticeable influence of the properties of the soil is detected in the displacements estimated. For example, a soil with $E=60 \mathrm{MPa}$ leads to a displacement $14.7 \%$ bigger than a soil with $100 \mathrm{MPa}$ (for a CLSM of $300 \mathrm{MPa}$ ). The curves indicate that the configuration of two layers of soil $(60-100 \mathrm{MPa})$ result in values of displacement that are in between of those obtained for one-layer soils of $60 \mathrm{MPa}$ and $100 \mathrm{MPa}$. According to Fig.6, the maximum displacement of the asphalt pavement occurs for the most flexible soil $(E=60 \mathrm{MPa})$ and $\operatorname{CLSM}(E=100 \mathrm{MPa})$ with a value of $1.3 \mathrm{~mm}$.

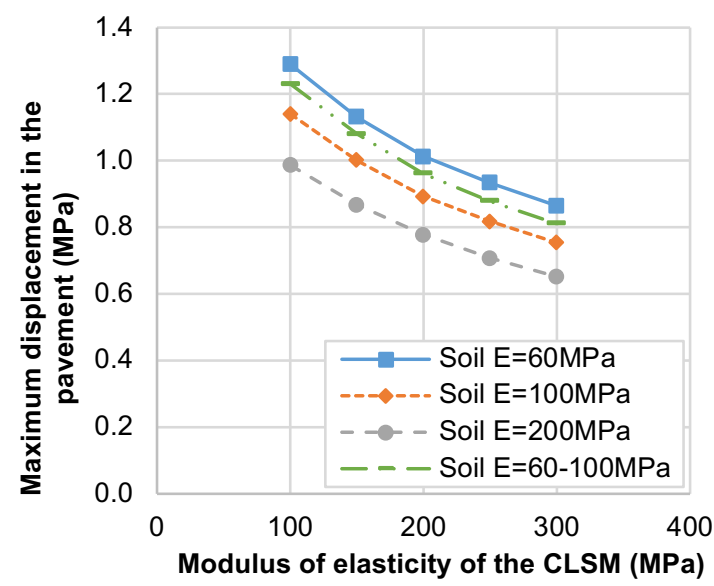

Fig. 7 Influence of the modulus of elasticity of the CLSM on the compressive stress in the pipeline.

From the results it may be derived that the maximum compressive stresses due to the heavy traffic loading in service is $1.12 \mathrm{MPa}$. Consequently, a compressive strength of the CLSM equal to that value would be sufficient to bear the stresses and to guarantee a maximum displacement of $1.3 \mathrm{~mm}$. Nevertheless, in order to avoid excessive microcracking (a non-linear regime) the maximum stresses in service are limited to a range of $45 \%-55 \%$ of the compressive strength, leading to a strength ranging between $2.0 \mathrm{MPa}$ and $2.5 \mathrm{MPa}$.

\section{Experimental program}

The main objective of this section is to apply the experimental procedure of the methodology to obtain an optimized CLSM that attends the requirements set in the previous section. According to the optimization procedure in the methodology this section 
is divided into three parts: the definition of the granular skeleton, the definition of the cement content and, finally, the definition of the additives and admixtures employed.

\subsection{Stage 1: Optimisation of the aggregates}

At this stage, the influence of the granular skeleton on the workability and the packing density of the CLSM is assessed by considering different combinations of the aggregates and several water/solid ratios $(\mathrm{w} / \mathrm{s})$.

\section{Materials and mix proportions}

The aggregates used in the study are limestone sands of $0 / 2$ and $0 / 4$ with a density of 2510 $\mathrm{kg} / \mathrm{m}^{3}$ and $2520 \mathrm{~kg} / \mathrm{m}^{3}$, respectively, and a water absorption of $7.20 \%$ and $5.50 \%$, respectively. They were combined in the percentages by volume of $80 \%-20 \%, 50 \%-50$ and $20 \%-80 \%$, respectively. The values of $\mathrm{W} / \mathrm{S}$ are $0.25,0.30,0.35,0.40$ and 0.45 , assuming a situation of saturated surface-dry conditions $(S S D)^{1}$. Likewise, the cement content of reference at this first stage is of $40 \mathrm{~kg} / \mathrm{m}^{3}$ (CEM II/A-M (V-L) $42.5 \mathrm{R}$ ), defined according to [5]. Table 3 presents the different mix compositions studied at this stage.

Table 3. Mix proportions in Stage 1.

\begin{tabular}{cc|ccc|ccc|ccc}
\cline { 3 - 11 } & & \multicolumn{3}{|c|}{ Case 1: 80\%-20\% } & \multicolumn{3}{c|}{ Case 2: 50\%-50\% } & \multicolumn{3}{c}{ Case 3: 20\%-80\% } \\
\hline$w / s$ & Cement & Sand 0/2 & Sand 0/4 & Water & Sand 0/2 & Sand 0/4 & Water & Sand 0/2 & Sand 0/4 & Water \\
\hline 0.25 & 40 & 1580 & 397 & 200 & 987 & 991 & 200 & 395 & 1586 & 200 \\
0.30 & 40 & 1518 & 381 & 231 & 949 & 952 & 231 & 380 & 1524 & 231 \\
0.35 & 40 & 1461 & 367 & 259 & 913 & 916 & 259 & 365 & 1467 & 259 \\
0.40 & 40 & 1408 & 353 & 286 & 880 & 883 & 286 & 352 & 1413 & 286 \\
0.45 & 40 & 1358 & 341 & 310 & 849 & 852 & 310 & 340 & 1364 & 310 \\
\hline
\end{tabular}

All CLSM were manufactured according the same procedure. The solid components were first introduced in the 5 litres mixer and then the water was added. These components were mixed during 1 minute and the mixer was stopped for 30 seconds to ensure that material is not adhered to the surface of the recipient. Then, the mixer is started again and after 1 minute the admixture is added. Finally, all the components are mixed for 2 minutes more.

1 The phenomenon of the aggregate water absorption is essential in the mix composition of mortars and concrete. If aggregates are added to the mix in dry conditions, part of the water will be absorbed by these aggregates until they are saturated. 


\section{Tests and results}

The tests conducted in this stage are the wet-packing test $[7,8]$ and the consistency test according to UNE-EN 1015-3:2000 [9], as previously described in the methodology. The results of the former are presented in Fig. 8 in terms of the solid concentration and the voids ratio, which were calculated according to the formulations in [17].
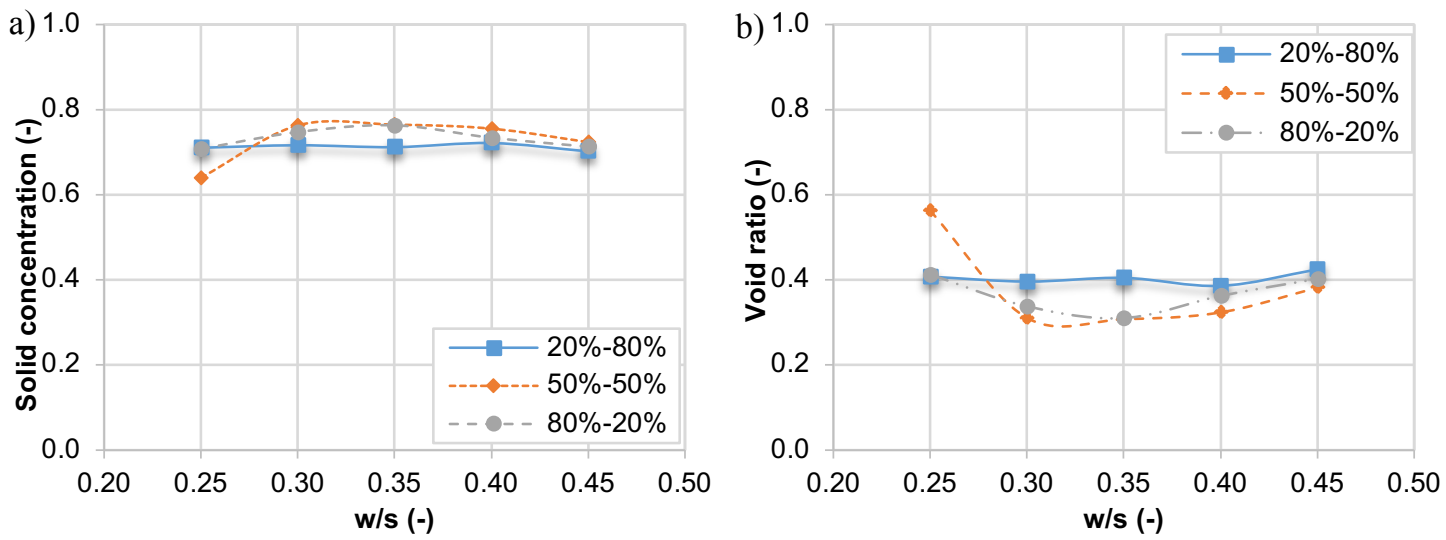

Fig.8. Influence of $w / s$ on a) solid concentration and b) void ratio.

From the results in Fig.8a and Fig. $8 \mathrm{~b}$ it may be derived that the different combinations of aggregate skeleton exhibit, in general, similar values for the solid concentration and the void ratio. Such outcome indicates that, in this case, employing one or another combination of aggregates skeleton may not lead to significant differences in the results. The highest solid concentration and the lowest voids ratio is obtained for a w/s equal to 0.35 , considering the granular skeletons of $20 \%-80 \%$ and of $50 \%-50 \%$. These values are 0.766 and 0.765 for the solid concentration, respectively, and 0.306 and 0.308 for the voids ratio, respectively.

Fig.9 depicts the results of the consistency test in terms of the flow extent for different values of w/s considered. It reveals a clear influence of w/s in the consistency of the CLSM with an approximate S-shaped curve. The range of w/s values in which the increase of workability is significant, as observed due to the steep slope of the curve, is $0.30-0.40$. For values higher than 0.40 , the addition of water is less efficient and might lead to bleeding. Notice that the flow extent for the case of $80 \%-20 \%$ with a w/s $=0.45$ is not depicted in Fig.9 since due to the fluidity of the mix it poured from the table. 


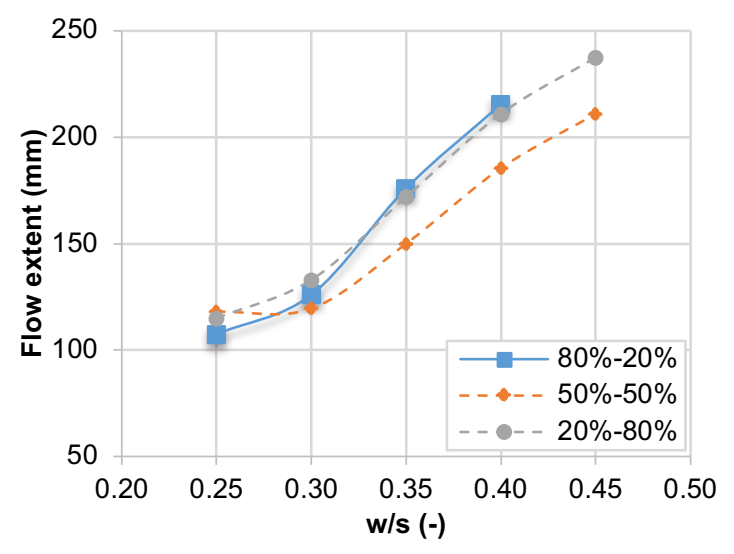

Fig.9. Influence of the $w / s$ in the flow extent.

This phenomenon is due to the physical role of the water in the mortar and concrete mixes $[22,23]$. The aggregates in the mix require a certain amount of water to fill the pores (absorption water) and to wet the surface (wetting water). Notice that in the case of study the aggregates are already saturated. When the surface of the aggregate is wet, the remaining water has the function of fluidifyng the mix (fluidification water) and, therefore, separating the particles. It should be highlighted that an excessive separation of the particles may lead to bleeding, a phenomenon that may be observed for high values of w/s.

From the values in Fig.9, it may be stated that the threshold value to start fluidifying the mix is around $\mathrm{W} / \mathrm{S}=0.3$. Fig. 10 shows the aspect of the CLSM with different $\mathrm{W} / \mathrm{S}$ values after the consistency test and confirms the lack of fluidification water in the case of Fig.10a.
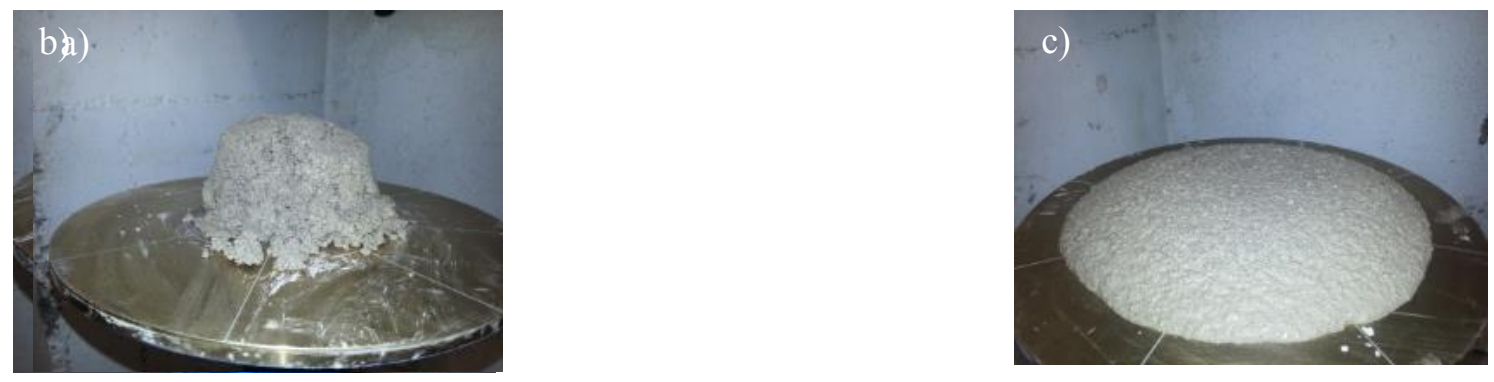

Fig. 10. Consistency test for $50 \%-50 \%$ and a) $\mathrm{W} / \mathrm{S}=0.25$, b) $\mathrm{W} / \mathrm{S}=0.35$ and c) $\mathrm{W} / \mathrm{S}=0.45$.

Taking into account the results of the consistency test and the wet-packing test, it may be derived that a combination of the aggregates of $50 \%$ of sand $0 / 2$ and $50 \%$ of sand $0 / 4$ may be suitable for the application considered. 


\subsection{Stage 2: Optimisation of the cement content}

The second stage of the experimental program focuses on the study of the minimum amount of cement that provides the minimum required compressive strength without compromising the excavability.

\section{Materials and mix proportions}

According to the ACI Committee 229 [1] the cement content in CLSM may vary between 30 and $120 \mathrm{~kg} / \mathrm{m}^{3}$ depending on the requirements set. Considering this range, the cement contents assessed and presented in an internal report [24] ranged from $40 \mathrm{~kg} / \mathrm{m}^{3}$ to 85 $\mathrm{kg} / \mathrm{m}^{3}$. For this study, only the results of the content of cement that fulfill the strength requirements are shown. Notice that the w/s was set to 0.37 and the proportion of aggregates $50 \%-50 \%$ was considered based on the results in Stage 1. The details of the mix proportions are included in Table 4.

Table 4. Mix proportions in Stage 2.

\begin{tabular}{lcc}
\hline \multicolumn{2}{c}{ Materials } & Quantities \\
\hline w/s & $(-)$ & 0.37 \\
Cement & $\left(\mathrm{kg} / \mathrm{m}^{3}\right)$ & 75 \\
Sand 0/2 & $\left(\mathrm{kg} / \mathrm{m}^{3}\right)$ & 885 \\
Sand $0 / 4$ & $\left(\mathrm{~kg} / \mathrm{m}^{3}\right)$ & 882 \\
Water & $\left(\mathrm{kg} / \mathrm{m}^{3}\right)$ & 270 \\
\hline
\end{tabular}

The mixing procedure of the components is the same as in the previous stage. In this case, 6 prismatic specimens of $40 \times 40 \times 160 \mathrm{~mm}$ were cast to determine the compressive strength following the specifications in UNE-EN 12390:2009 [19]. A total of 6 specimens were cast to be tested at 7 day, 21 days and 28 days.

Tests and results

The test performed in the second stage is the compression test (UNE-EN 12390:2009 [19]). The results of the compression test at 7 days, 21 days and 28 days are presented in Table 5. 
Table 5. Compressive strength of the CLSM with $75 \mathrm{~kg} / \mathrm{m}^{3}$ for 7,21 and 28 days.

\begin{tabular}{ccc}
\hline & Average (MPa) & CV (\%) \\
\hline$f_{c 7}$ & 1.9 & 5.3 \\
$f_{c 21}$ & 1.9 & 6.1 \\
$f_{c 28}$ & 2.1 & 4.8 \\
\hline
\end{tabular}

The results obtained indicate a compressive strength of $1.9 \mathrm{MPa}$ both at 7 day and 21 days. The tests conducted at 28 days reveal a strength of the CLSM of $2.1 \mathrm{MPa}$. These values are in correspondence with the requirements set based on the results of the numerical model. Hence, a content of cement of $75 \mathrm{~kg} / \mathrm{m}^{3}$ guarantees the bearing of stresses resulting of the traffic load in the trench.

\subsection{Stage 3: Optimisation of admixtures and additions}

The final stage of the methodology studies the influence of the admixtures and additions on the properties of the CLSM. In this case, the experimental program only considers the influence of plasticizer (Pozzolith $475 \mathrm{~N}$ ) on the consistency and workability of the CLSM. However, the methodology may be applied to any additions by assessing their influence on the consistency, compressive strength and, if required, evaluating particular properties provided by the addition.

\section{Materials and mix proportions}

The mixes manufactured in the previous section 4.1 Stage 1: Optimisation of the aggregates were produced with $1.5 \%$ of plasticizer (in percentage of the cement weight). The other components of the mixes were added in the same proportions as in the previous case.

\section{Test and results}

The assessment of the influence of the plasticizer was conducted by means of the consistency test according to the UNE-EN 1015-3:2000 [17]. The curves showing the evolution of the diameter with w/s are depicted in Fig. 11. 
a)

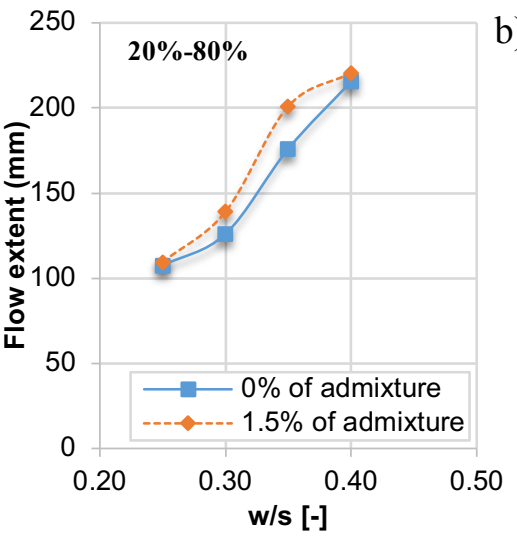

b)

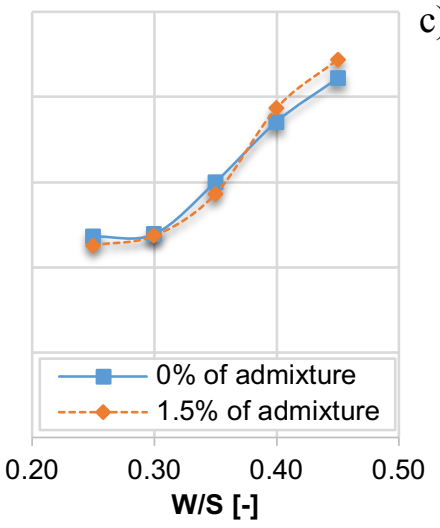

c)

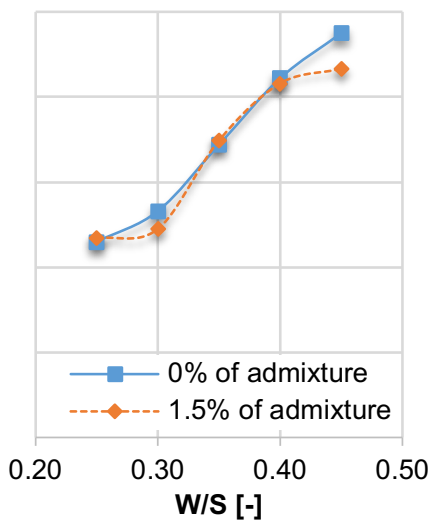

Fig. 11. Influence of the admixture in the consistency of the CLSM for a) $20 \%-80 \%$, b) $50 \%$ -

$$
50 \%, 80 \%-20 \% \text {. }
$$

The curves reveal that the influence of the plasticizer is almost unnoticeable on the consistency of the CLSM since the values of flow extent are very similar. Notice that the differences in average between the flow extent of the mixes without and with admixture are $7.2 \%$ for the case $20 \%-80 \%, 0.8 \%$ for the case $50 \%-50 \%$ and -3.5 for the case $80 \%$ $20 \%$.

In conventional concrete, the plasticizers produce a dispersion of the cement particles that otherwise would tend to form agglomerations and reduce the plasticity of the mix. In the case of CLSM, the small cement content and the high amount of water should reduce considerably the likelihood of particle interaction and flocculation. Therefore, the effect of the plasticizers should be less noticeable in CLSM.

\section{Conclusions}

The study conducted represents a contribution to the design of CLSM with optimised mix proportions. Furthermore, the methodology proposed allows a technical base assessment of the requirements associated to the application and provides the tests required to optimise the mix while fulfilling the requirements set. The following conclusions may be derived from the present study:

- The results of the numerical model confirm that a compressive strength ranging between $2.0 \mathrm{MPa}-2.5 \mathrm{MPa}$ would ensure stability and excavability.

- The critical zones of loading in the surrounding soil and in the CLSM of the trench were identified.

- The load in the pipeline is much smaller and would only be a problem if it was transmitted through point-like aggregates. 
- The consistency tests performed in Stage 1 of the experimental procedure for the optimisation of the mix revealed a range of values of $\mathrm{w} / \mathrm{s}(0.35-0.40)$ leading to a suitable workability.

- The compression tests performed in Stage 2 reveal that a content of cement of 75 $\mathrm{kg} / \mathrm{m}^{3}$ is enough to fulfil the strength requirements obtained from the model.

- The use of plasticizers to improve the workability was found to be inefficient for this type of material with low contents of cement, based on the results obtained in the test conducted in Stage 3.

The methodology was successfully applied to the backfill of narrow trenches but could be also employed to design other types of CLSM that may include new materials (e.g. waste materials or industrial by-products) and to different applications.

\section{Acknowledgements}

The authors of this paper want to acknowledge the financial support provided by Gas Natural Fenosa (GNF) and, in particular, the comments and conversations with Jordi Rosselló and Carlos Aranda.

\section{References}

[1] Siddique R. Utilization of waste materials and by-products in producing controlled lowstrength materials. Resour Conserv Recy 2009; 54: 1-8.

[2] ACI Committee 229. Controlled low-strength materials (ACI 229R-99). Farmington Hills (MI): American Concrete Institute; 1999.

[3] Federal Highway Administration. User Guidelines for Waste and By-Product Materials in Pavement Construction. U.S. DOT. Report No. FHWA-RD-97-148; 1997.

[4] Alizadeh A, Helwany S, Ghorbanpoor A, Sobolev K. Design and application of controlled low strength materials as a structural fill. Constr Build Mater 2014; 53: 425-431.

[5] Blakaya M, Moore ID, Sağlamer A. Study of non-uniform bedding due to voids under jointed PVC water distribution pipes. Geotext Geomembranes 2012; 35: 99-108.

[6] Balkaya M, Moore ID, Sağlamer A. Study of non-uniform bedding support under continuous PVC water distribution pipes. Tunn Undergr Sp Tech 2013; 35: 99-108.

[7] Fung WWS, Kwan AKH, Wong HHC. Wet packing of crushed rock fine aggregate. Mater Struct 2009; 42: 631-643.

[8] Wong HHC, Kwan AKH. Packing density of cementitious materials: part 1 - measurement using a wet packing method. Mater Struct 2008; 41: 689-701.

[9] AENOR.UNE-EN 1015-3:2000 Métodos de ensayo para morteros de albañilería. Parte 3: Determinación de la consistencia del mortero fresco (por la mesa de sacudidas), Asociación Española de Normalización y Certificación, Madrid, 2005. 
[10] AENOR. UNE-EN 12390:2009 Ensayos de hormigón endurecido. Parte 3: Determinación de la resistencia a compresión de probetas, Asociación Española de Normalización y Certificación, Madrid, 2009.

[11] Etxebarria M, Ainchil J, Pérez ME, González A. Use of recycled fine aggregates for Control Low Strength Materials (CLSMs) production. Constr Build Mater 2013; 44:142148.

[12] Taha RS, Alnuaimi AS, Al-Jabri KS, Al-Harthy AS. Evaluation of controlled low strength materials containing industrial by-products. Build Environ 2007; 42: 3366-3372.

[13] Nataraja MC, Nalanda Y. Performance of industrial by-products in controlled low-strength materials (CLSM). Waste Manage 2008; 28: 1168-1181.

[14] Wang H-Y, Chen B-T, Wu Y-W. A study of the fresh properties of controlled low-strength rubber lightweight aggregate concrete (CLSRLC). Constr Build Mater 2013; 41: 526-531.

[15] Lee NK, Kim HK, Park IS, Lee HK. Alkali-activated, cementless, controlled low-strength materials (CLSM) utilizing industrial by-products. Constr Build Mater 2013; 49: 738-746.

[16] Bouzalakos S, Dudeney AWL, Chan BKC. Formulating and optimizing the compressive strength of controlled low-strength materials containing mine tailings by mixture design and response surface methods. Miner Eng 2013, 53: 48-56.

[17] TNO Diana BV. Diana User's Manual, 2008 (http://www.tnodiana.com/)

[18] Kraemer C, Pardillo JM, Rocci S, Romana MG, Blanco VS, del Val MA. Ingeniería de Carreteras, Volumen II. $1^{\text {a }}$ ed.; Madrid: McGraw-Hill Interamericana de España, S.A.U; 2003.

[19] Jiménez Salas JA, Justo Alpañés JL. Geotencia y cimientos I. 2 ${ }^{\text {a }}$ ed.; Madrid: Rueda; 1975.

[20] España. Real Decreto 2822/1998, de 23 de diciembre, por el que se aprueba el Reglamento General del Vehículos. Boletín Oficial del Estado, 26 de enero de 1999, núm. 22, pp. 34843447.

[21] France. Loi no $55-435$ du 18 avril 1955 portant statut des routes.

[22] Fennis SAAM. Design o f Ecological Concrete by Particle Packing Optimization, Doctoral Thesis, Delft University of Technology, Delft, 2011.

[23] Klein N. El Rol físico del agua en mezclas de cemento Portland, Doctoral Thesis, Universitat Politècnica de Catalunya, Barcelona, 2012.

[24] Aguado A, Blanco A, Cavalaro S, Pujadas P. Desarrollo de mortero de relleno para zanjas de dimensiones reducidas, Internal Report, Universitat Politècnica de Catalunya, Barcelona, 2013. 